\title{
Severe stress switches CRF action in the nucleus accumbens from appetitive to aversive.
}

\author{
Julia C Lemos \\ University of Washington \\ Matthew J Wanat \\ University of Washington \\ Jeffrey S Smith \\ University of Washington \\ Beverly A S Reyes \\ Thomas Jefferson University \\ Aligk $G$ thellugnd additional works at: https://jdc.jefferson.edu/farberneursofp \\ IIniversity of Washington \\ Part of the Psychiatry Commons

\section{Let us know how access to this document benefits you See next page for additional authors}

\section{Recommended Citation}

Lemos, Julia C; Wanat, Matthew J; Smith, Jeffrey S; Reyes, Beverly A S; Hollon, Nick G; Van Bockstaele, Elisabeth J; Chavkin, Charles; and Phillips, Paul E M, "Severe stress switches CRF action in the nucleus accumbens from appetitive to aversive." (2012). Farber Institute for Neurosciences Faculty Papers. Paper 14.

https://jdc.jefferson.edu/farberneursofp/14

This Article is brought to you for free and open access by the Jefferson Digital Commons. The Jefferson Digital Commons is a service of Thomas Jefferson University's Center for Teaching and Learning (CTL). The Commons is a showcase for Jefferson books and journals, peer-reviewed scholarly publications, unique historical collections from the University archives, and teaching tools. The Jefferson Digital Commons allows researchers and interested readers anywhere in the world to learn about and keep up to date with Jefferson scholarship. This article has been accepted for inclusion in Farber Institute for Neurosciences Faculty Papers by an authorized administrator of the Jefferson Digital Commons. For more information, please contact: JeffersonDigitalCommons@jefferson.edu. 


\section{Authors}

Julia C Lemos, Matthew J Wanat, Jeffrey S Smith, Beverly A S Reyes, Nick G Hollon, Elisabeth J Van Bockstaele, Charles Chavkin, and Paul E M Phillips 


\title{
Severe stress switches CRF action in the nucleus accumbens from appetitive to aversive
}

\author{
Julia C. Lemos ${ }^{1,2,3}$, Matthew J. Wanat ${ }^{1,2}$, Jeffrey S. Smith ${ }^{2}$, Beverly A. S. Reyes ${ }^{4}$, Nick G. Hollon ${ }^{1,2,3}$, Elisabeth J. Van Bockstaele ${ }^{4}$, \\ Charles Chavkin ${ }^{2,3}$ \& Paul E. M. Phillips ${ }^{1,2,3}$
}

\begin{abstract}
Stressors motivate an array of adaptive responses ranging from 'fight or flight' to an internal urgency signal facilitating long-term goals ${ }^{1}$. However, traumatic or chronic uncontrollable stress promotes the onset of major depressive disorder, in which acute stressors lose their motivational properties and are perceived as insurmountable impediments ${ }^{2}$. Consequently, stress-induced depression is a debilitating human condition characterized by an affective shift from engagement of the environment to withdrawal ${ }^{3}$. An emerging neurobiological substrate of depression and associated pathology is the nucleus accumbens, a region with the capacity to mediate a diverse range of stress responses by interfacing limbic, cognitive and motor circuitry ${ }^{4}$. Here we report that corticotropin-releasing factor (CRF), a neuropeptide released in response to acute stressors ${ }^{5}$ and other arousing environmental stimuli ${ }^{6}$, acts in the nucleus accumbens of naive mice to increase dopamine release through coactivation of the receptors CRFR1 and CRFR2. Remarkably, severe-stress exposure completely abolished this effect without recovery for at least $\mathbf{9 0}$ days. This loss of CRF's capacity to regulate dopamine release in the nucleus accumbens is accompanied by a switch in the reaction to CRF from appetitive to aversive, indicating a diametric change in the emotional response to acute stressors. Thus, the current findings offer a biological substrate for the switch in affect which is central to stress-induced depressive disorders.
\end{abstract}

CRF initiates neuroendocrine signalling in the hypothalamicpituitary-adrenal axis and also regulates neurotransmission directly through two receptor subtypes, CRF receptor 1 (CRFR1) and CRFR2, which are distributed widely throughout the $\operatorname{brain}^{7,8}$. In the nucleus accumbens, CRF facilitates cue-elicited motivation ${ }^{9}$ and social bonding $^{10}$, behaviours that are thought to be mediated by dopamine transmission $^{11,12}$. Therefore, we sought evidence for CRF-dopamine interactions in the nucleus accumbens, first using fluorescent immunohistochemistry. Dense CRF immunoreactivity was present throughout the rostro-caudal axis of the nucleus accumbens core and lateral shell, and in the most rostral portion of the medial shell in sparsely located large cell bodies (cholinergic interneurons, see Supplementary Fig. 1) and fibre terminals that were interdigitated with tyrosine-hydroxylase-immunoreactive fibres that are indicative of dopamine-containing axons (Fig. 1a). Immunoreactivity for the CRFR1 receptor displayed punctate staining with co-localization of tyrosine-hydroxylase immunoreactivity on fibre segments in addition to localization on cell bodies within the nucleus accumbens (Fig. 1b and Supplementary Fig. 2). CRFR2 immunoreactivity had a more diffuse but still punctate pattern of staining, similar to that in other regions $^{13}$, with some co-localization with tyrosine-hydroxylase immunoreactivity (Fig. 1c and Supplementary Fig. 3). Expression of CRF receptors on subcellular profiles in the nucleus accumbens, including tyrosine-hydroxylase-positive terminals, was confirmed at higher spatial resolution using transmission electron microscopy (Fig. 1d; quantified in Supplementary Table 1). Together, these data indicate that the localization of CRF and its receptors in the nucleus accumbens is well-suited for modulation of dopamine release.

To directly test the functional effects of CRF on dopamine release in the nucleus accumbens, we selectively monitored dopamine release evoked by a single biphasic electrical pulse ( 2 ms per phase, $100-$ $500 \mu \mathrm{A}$ delivered once per minute) in acute coronal brain slices using fast-scan cyclic voltammetry at carbon-fibre microelectrodes (Fig. 2a and Supplementary Fig. 4). Vehicle or CRF (10, 100 or 1,000 nM) was applied to the slice for $15 \mathrm{~min}$ after $5 \mathrm{~min}$ of stable baseline, and the resultant effect was quantified by averaging the evoked dopamine current in the last 10 minutes. After application of vehicle, there was a modest $(\sim 7 \%)$ decrease in dopamine release (Fig. $2 b)$, whereas CRF increased dopamine release in a concentration-dependent manner eliciting effects significantly greater than vehicle at 100 and $1,000 \mathrm{nM}(27.8 \pm 6.7$ and $30.0 \pm 8.4 \%$, respectively, mean \pm s.e.m.; $F_{3,49}=5.026, P<0.01$, one-way analysis of variance (ANOVA) with Dunnett's post-hoc $t$-tests; Fig. $2 \mathrm{~b}$ and Supplementary Fig. 5). Interestingly, this effect could be blocked by application of either the selective CRFR1 antagonist, antalarmin $(1 \mu \mathrm{M})$, or the selective CRFR2 antagonist, anti-sauvagine 30 (ASVG 30;250 nM), to the slice beginning $20 \mathrm{~min}$ before CRF application $\left(F_{2,50}=5.142, P<0.01\right.$, one-way ANOVA with Dunnett's post-hoc $t$-tests; Fig. 2c) indicating that coactivation of both receptors is required. Consistently, CRF (10,
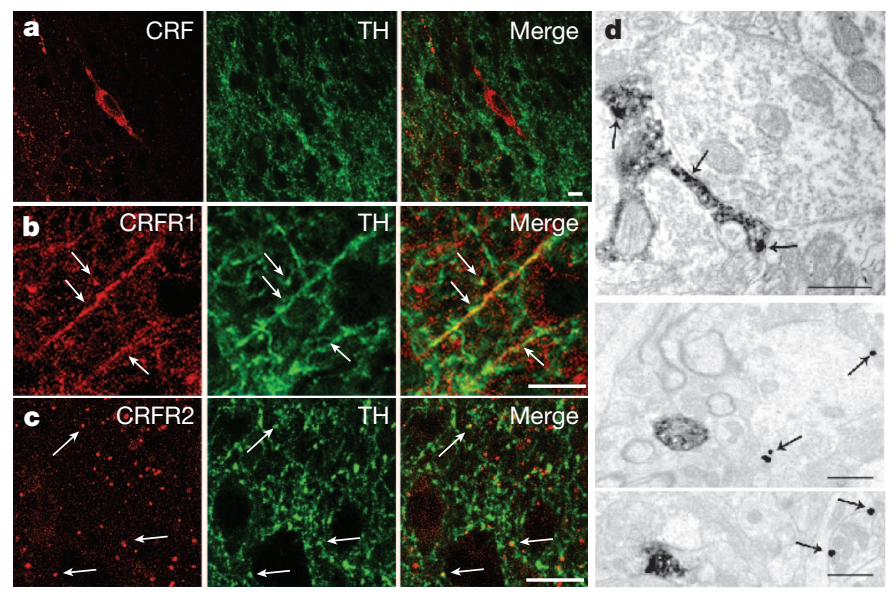

Figure $1 \mid$ Cellular localization of CRF peptide, CRFR1 and CRFR2 in the nucleus accumbens. a-c, Immunoreactivity for CRF peptide (top), CRFR1 (middle) or CRFR2 (bottom) is shown in red and for tyrosine hydroxylase (TH) is shown in green. Arrows highlight examples of co-localization (yellow in the merged images). Scale bars, $10 \mu \mathrm{m}$. d, Transmission electron microscopy photomicrographs showing CRF receptors (labelled with immunogold particles; arrows) present on both TH-positive (immunoperoxidase labelled) and TH-negative profiles. Scale bars, $0.5 \mu \mathrm{m}$ (top panel) and $1 \mu \mathrm{m}$ (bottom panels). 
a
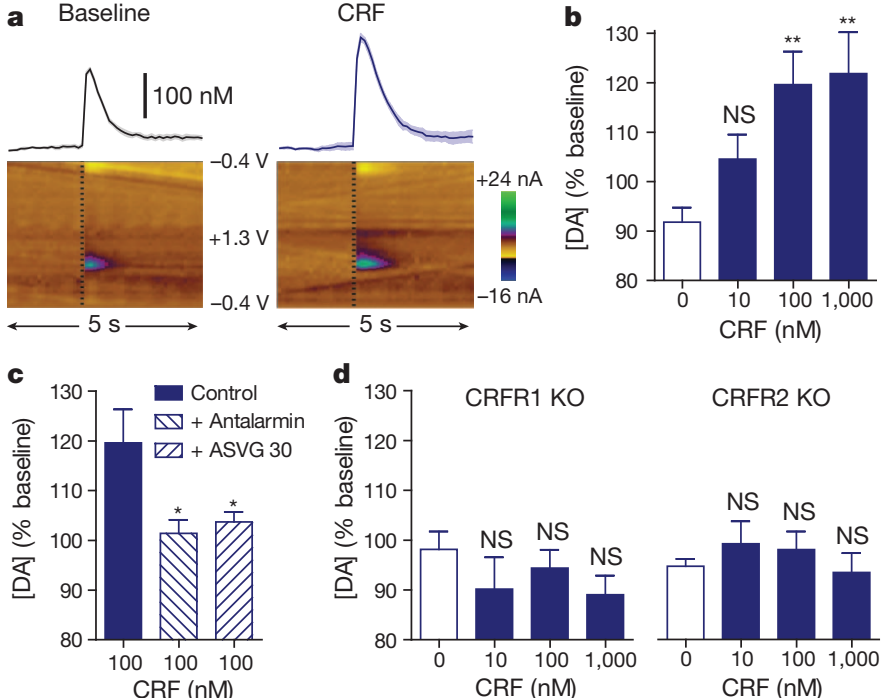

d
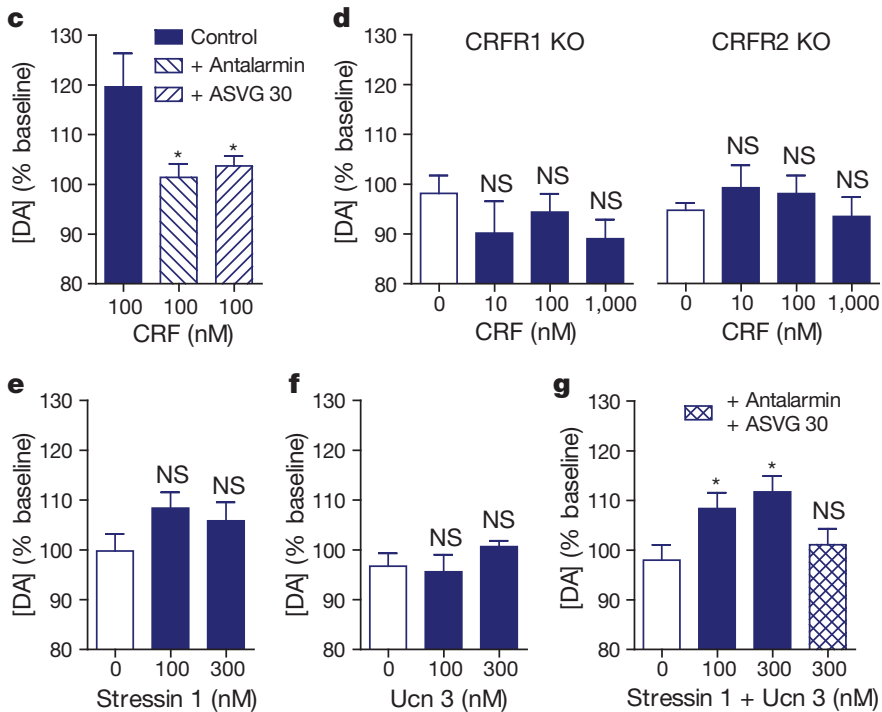

Figure $2 \mid$ CRF increases dopamine release in the nucleus accumbens through coactivation of CRFR1 and CRFR2. a, Representative dopamine release evoked by electrical stimulation (dashed lines) before (left) and after (right) application of $100 \mathrm{nM} \mathrm{CRF} \mathrm{(mean} \pm$ s.e.m. for 5 consecutive stimulations, top) and corresponding two-dimensional plots depicting changes in faradaic current (pseudocolour) with time as the abscissa and applied potential as the ordinate (bottom). b. Concentration response to CRF, $n=11-$ 18. c, Effect of antagonists for CRFR1 (antalarmin, $1000 \mathrm{nM}$ ) or CRFR2 (antisauvagine 30 (ASVG 30), $250 \mathrm{nM}$ ), $n=18-20$. d, CRF in mice lacking the gene encoding the CRFR1 (left) or CRFR2 (right) receptors, $n=7-13$. e-g, Effect of the CRFR1 agonist, stressin 1, $n=9-15$ (e), the CRFR2 agonist, urocortin 3 (100 or $300 \mathrm{nM}$ ), $n=5-8$ (f) or their co-application, $n=8-15$ (g). Error bars, s.e.m. DA, dopamine; NS, not significant (with $P>0.05$ ); ${ }^{*} P<0.05$; $* * P<0.01$ versus vehicle.

$100,1,000 \mathrm{nM}$ ) failed to increase dopamine release in the nucleus accumbens of mice with deletion of either the Crfr1 (ref. 14) or Crfr2 (ref. 15) gene (Fig. 2d). Application of the selective CRFR1 agonist stressin 1 (100 or $300 \mathrm{nM}$ ) or the selective CRFR2 agonist urocortin $3(100$ or $300 \mathrm{nM})$ failed to significantly increase dopamine release when applied individually $(P>0.05$ compared to respective vehicles; Fig. 2e, f), but significantly increased dopamine release when applied together $\left(F_{3,36}=3.528, P<0.05\right.$ versus vehicle, one-way ANOVA with Dunnett's post-hoc $t$-tests). The effect of the agonists together could be blocked by pre-treatment with antalarmin and ASVG 30 (unpaired $t$-test, $P>0.05$; Fig. $2 \mathrm{~g}$ ). Together these data provide convergent evidence that CRF increases dopamine release in the nucleus accumbens through coactivation of CRFR1 and CRFR2.

If this ability for CRF to positively regulate dopamine in the nucleus accumbens has specific motivational relevance to the behaving animal, we would predict that it would cause conditioned place preference when restricted to the nucleus accumbens, even though centrally administered CRF elicits robust conditioned place aversion ${ }^{16}$. Therefore, we used a balanced place-conditioning apparatus consisting of two visually distinct test chambers separated by a smaller neutral compartment. On day one, mice were allowed to freely roam the apparatus, and the time they spent in each chamber was recorded.

On days two and three, mice received CRF bilaterally into the nucleus accumbens (500 ng per side in $200 \mathrm{nl}$ artificial cerebrospinal fluid; cannulae placements are shown in Supplementary Fig. 6) or vehicle infusions and were then isolated in one of the test chambers for $30 \mathrm{~min}$. Four hours later they received the alternative infusion and were isolated in the other test chamber for $30 \mathrm{~min}$. On day four, mice were again allowed free access to the apparatus. Following conditioning, mice exhibited a significant preference for the CRF-paired context, demonstrating that intra-accumbens CRF (500 ng) was an appetitive stimulus to these animals (conditioning by drug, $F_{1,12}=6.435$, $P<0.001$, two-way repeated-measures ANOVA; Fig. 3a). Similarly, unilateral infusions of CRF ( $500 \mathrm{ng}$ in $200 \mathrm{nl}$ ) also produced conditioned place preference (conditioning by drug, $F_{1,12}=11.77, P<0.001$ twoway repeated-measures ANOVA; Fig. $3 \mathrm{~b}$ and Supplementary Fig. 7a). This dose of CRF is within the range that produces selective effects in $v i v o^{9}$, but it is difficult to ascertain the steady-state concentration at receptors as CRF undergoes both radial diffusion and active clearance ${ }^{17}$. Nevertheless, even at a lower dose of CRF ( $5 \mathrm{ng}$ in $200 \mathrm{nl}$ ), conditioned place preference was observed (conditioning by drug, $F_{1,14}=5.415$, $P<0.05$, two-way repeated-measures ANOVA; Fig. $3 \mathrm{~b}$ and Supplementary Fig. 7b). Taken together, these data indicate that CRF acts in the nucleus accumbens to produce a positive affective state.

To test whether this positive affective state is dependent upon CRF's ability to increase dopamine release, we used the catecholaminergicneuron-selective neurotoxin, 6-hydroxydopamine (6-OHDA). We compared unilateral CRF place conditioning in animals that had received ipsilateral infusions of 6-OHDA $(2 \mu \mathrm{g}$ in $500 \mathrm{nl})$ versus vehicle $(0.09 \% \mathrm{NaCl}, 0.1 \%$ ascorbate $)$ into the nucleus accumbens 7 days earlier. CRF (500 ng in $200 \mathrm{nl}$ ) produced place preference in sham animals (conditioning by drug, $F_{1,18}=6.95, P<0.05$ two-way repeated-measures ANOVA; Supplementary Fig. 8a), of similar magnitude to controls (treatment by drug, $F_{1,30}=0.35, P>0.05$, two-way ANOVA). However, place preference to intra-accumbens CRF was absent in animals that received 6-OHDA (conditioning by drug, $F_{1,18}=0.00, P>0.05$, two-way repeated-measures ANOVA; Supplementary Fig. $8 \mathrm{~b}$ ) showing a significant change in the subjective effects of CRF ( $P<0.05$, unpaired $t$-test; Fig. $3 \mathrm{~b})$. This 6-OHDA treatment produced a significant dopamine depletion on the side of the injection $(P<0.001$; Supplementary Fig. 8c), but did not alter locomotor activity $(P>0.05$, unpaired $t$-test; Supplementary Fig. $8 \mathrm{~d})$, demonstrating that the unilateral lesions did not produce a general deficit in motor function. These data demonstrate that the positive affective state produced by CRF in the nucleus accumbens is dependent on its ability to increase dopamine release.

To ascertain the role of endogenously released CRF in the nucleus accumbens in mediating appetitive behaviours, we tested the effect of CRF antagonism on the response to an arousing stimulus by assaying novel object exploration, a behaviour that requires intact dopamine transmission ${ }^{18}$. We bilaterally infused the CRF antagonist, $\alpha$-helical CRF (500 ng in $200 \mathrm{nl}$ per side) or vehicle (lactated ringer's with $1 \%$ acetic acid), into the nucleus accumbens, placed animals into an arena, and then $15 \mathrm{~min}$ later introduced a novel object into the centre. Although $\alpha$-helical CRF had no effect on baseline exploration of the centre of the arena compared to vehicle, it significantly attenuated the appetitive effects (that is, eliciting of approach and exploration) of the novel object (treatment by stimulus, $F_{1,18}=4.62, P<0.05$, two-way repeated-measures ANOVA; Fig. 3c). These data demonstrate that endogenous CRF in the nucleus accumbens is used under physiological conditions to mediate appetitive responses to arousing environmental stimuli.

Exposure to severe or chronic stress can produce profound alterations in normal stress signalling that can be detrimental to physical and mental health, predisposing individuals to depression ${ }^{19}$. To model this phenomenon, we used a modified Porsolt paradigm in which mice are exposed to 2 days of repeated swim stress. Animals were placed in a vessel of water $\left(29-31^{\circ} \mathrm{C}\right)$ for $15 \mathrm{~min}$ followed by four additional 
a $\square$ Vehicle-paired chamber CRF-paired chamber

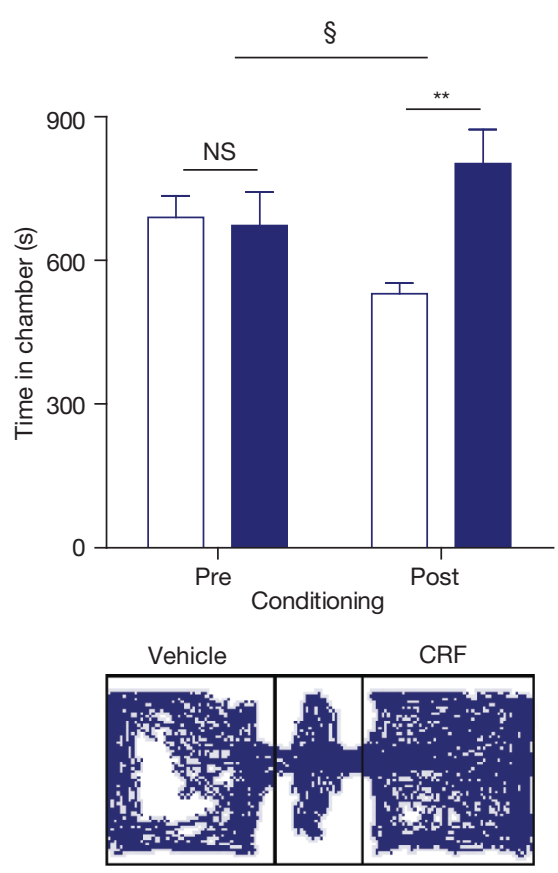

Figure $3 \mid \mathrm{CRF}$ in the nucleus accumbens promotes appetitive behaviour. a, Mean difference in times spent in the CRF-paired chamber compared to the vehicle-paired chamber before and after conditioning (top panel; $n=7$ ) and representative post-conditioning activity trace (bottom panel). b, Place

preference (time in CRF-paired chamber minus the time spent in the vehiclepaired chamber post conditioning) for intra-nucleus accumbens injections of $500 \mathrm{ng}$ CRF bilateral, $500 \mathrm{ng}$ unilateral or $5 \mathrm{ng}$ bilateral (left panel; $n=7-10$ ).

6-min swim sessions (separated by 6-min recovery periods) $24 \mathrm{~h}$ later. This protocol has been shown to produce escalating immobility across sessions, indicating a depression-like phenotype ${ }^{20}$. We prepared coronal slices of the nucleus accumbens from these animals 30 minutes after the final stress exposure and found that the ability for CRF to potentiate dopamine release was completely abolished (stress exposure by drug, $F_{4,116}=12.61, P<0.001$ two-way ANOVA; Fig. 4a). Notably, we established that this change in the ability of CRF to regulate dopamine release was not a generalized change in stress-related peptide signalling as the effect of a $\kappa$-opioid agonist to reduce dopamine release was unaffected by the 2-day stress-exposure paradigm (Supplementary Fig. 9). Therefore, these data show that severe stress selectively abolishes CRF's ability to modulate dopamine release in the nucleus accumbens. Surprisingly, there was no recovery of the action of CRF on dopamine release in the nucleus accumbens 7, 30 or even 90 days after stress exposure (stress exposure by drug, $F_{4,116}=4.852, P$ $<0.01$, two-way ANOVA; Fig. 4a). This time period is consistent with the protracted course of stress-induced depressive disorders ${ }^{21}$, and indeed, a depression-like phenotype was maintained across this 90-day post-stress period, as assessed by swim immobility (Supplementary Fig. 10). Importantly, the loss of the CRF response was not due to a baseline change in evoked dopamine release (Supplementary Fig. 11) and it was not simply an age-related phenomenon (Supplementary Fig. 12). Therefore, we have shown that severe stress produces a persistent dysregulation of CRF-dopamine interactions that normally produce a positive affective state.

Stress-induced depressive disorders are associated with altered levels of several neurochemicals that interact with the CRF system, including serotonin ${ }^{22}$, dynorphin ${ }^{23}$ and glucocorticoids ${ }^{4,24}$. Therefore, we targeted these systems to gain mechanistic insight into the stressinduced loss of CRF's regulation of dopamine release. We pretreated
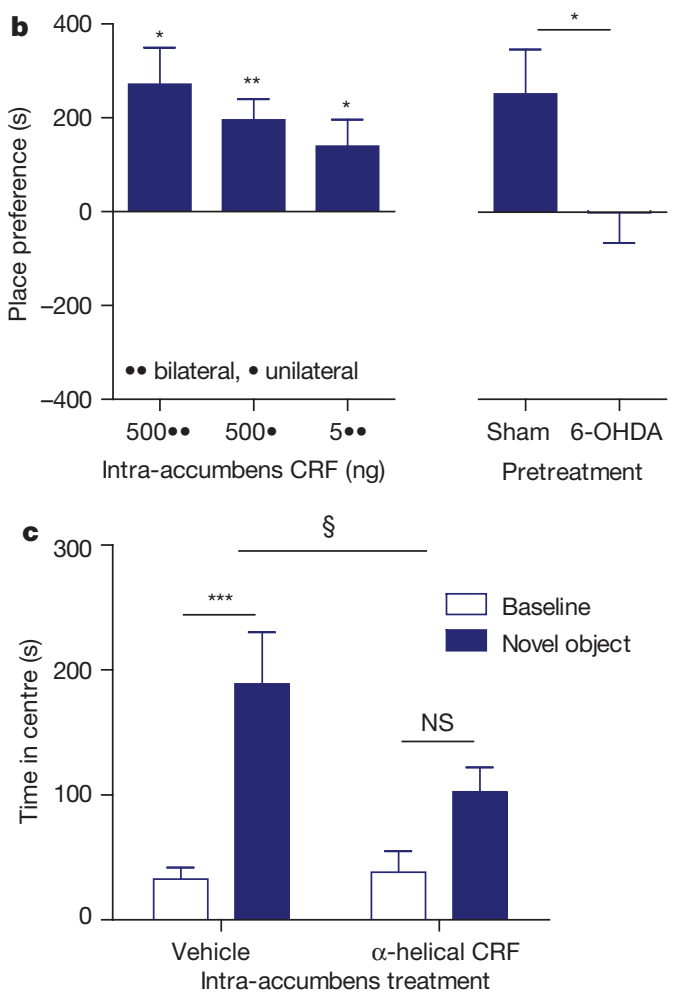

Place preference for $500 \mathrm{ng}$ CRF (unilateral) in sham or 6-OHDA-treated mice (right; $n=10$ ). c, Time spent in the centre of an open field before and during presentation of a novel object (placed in the centre of the field) after bilateral intra-accumbens infusion of the CRF-receptor antagonist $\alpha$-helical CRF $(500 \mathrm{ng})$ or its vehicle $(n=10)$. Error bars, s.e.m. NS, $P>0.05 ;{ }^{*} P<0.05$; $* * P<0.01 ; * * * P<0.001 ; \S P<0.05$ for interaction.

animals ( $10 \mathrm{ml} \mathrm{kg}^{-1}$ intraperitoneal) with vehicle, fluoxetine (selective serotonin-reuptake inhibitor; $10 \mathrm{mg} \mathrm{kg}^{-1}$ ), norBNI ( $\kappa$-opioid-receptor antagonist; $10 \mathrm{mg} \mathrm{kg}^{-1}$ ) or RU486 (glucocorticoid-receptor antagonist; $30 \mathrm{mg} \mathrm{kg}^{-1}$ ) before stress exposure on each of the swim-stress days. The animals were allowed to recover for 7 days, then slices were prepared and the CRF response was tested. Although acute regimens of fluoxetine do not alleviate pre-existing depression-related symptoms in patients or animal models, they have been shown to prevent the induction of some depression-like responses to stress ${ }^{25}$. Nevertheless, this treatment did not affect the abolition of CRF modulation of dopamine release by stress ( $P>0.05$; Supplementary Fig. 13). Similarly, this stress-induced perturbation was not significantly affected by norBNI ( $P>0.05$; Supplementary Fig. 13); however, it was prevented by RU486 (30 $\mathrm{mg} \mathrm{kg}^{-1}$; $P<0.001$; Fig. 4a and Supplementary Fig. 13), even at a lower dose $\left(10 \mathrm{mg} \mathrm{kg}^{-1} ; P<0.01\right.$; Supplementary Fig. 13). These data show that glucocorticoid signalling is a critical component of the profound stress-induced dysregulation of CRF-dopamine interactions in the nucleus accumbens.

This robust loss of the neurochemical response to CRF in the nucleus accumbens after severe stress suggests a long-lasting alteration in its subjective qualities. To test this idea, we used the placeconditioning paradigm in animals that had been exposed to the 2 -day swim-stress regimen. Mice that underwent repeated swim stress 7 days before conditioning spent significantly less time in the CRFpaired chamber than in the vehicle-paired chamber after conditioning, establishing that CRF in the nucleus accumbens is now aversive to these animals (conditioning by drug, $\mathrm{F}_{1,10}=5.824, P<0.01$, twoway ANOVA, Supplementary Fig. 14a). Therefore, severe stress produces a diametric shift in the subjective qualities of CRF in the nucleus accumbens from positive to negative (Fig. 4b). Consistent with the enduring loss of CRF regulation of dopamine observed in vitro, the 

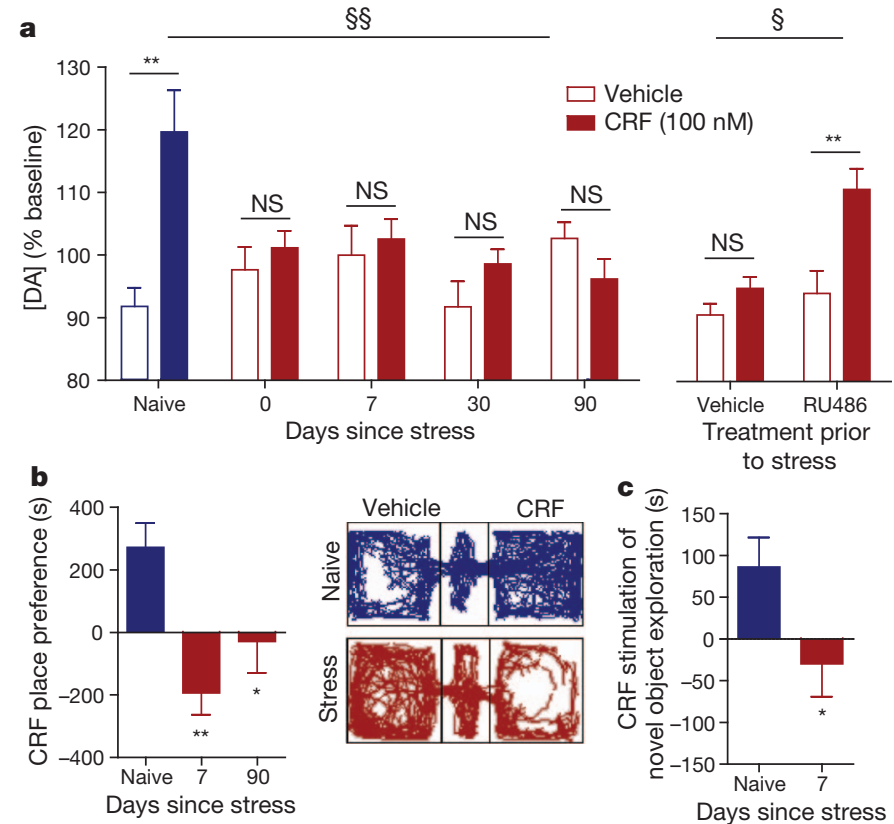

Figure $4 \mid$ Stress exposure abolishes the CRF-mediated increase in evoked dopamine release and subsequent appetitive behaviours. a, Effect of CRF on dopamine release in naive mice (blue) and after swim stress (red) (left panel; $n=8-18$ ), and in animals that were pretreated with the glucocorticoidreceptor antagonist, RU486 (30 $\mathrm{mg} \mathrm{kg}^{-1}$, intraperitoneal) or its vehicle before stress (right panel; $n=6-10)$. b, Mean place preferences for intra-accumbens $\mathrm{CRF}$ in naive (blue) and stress-exposed mice (red) (left panel; $n=6-8$ ) and representative activity traces (right). c, Difference in the increased centre time during presentation of a novel object between vehicle and CRF-receptor antagonism in naive (blue) animals and in animals 7 days post stress (red) $(n=9-10)$. Error bars, s.e.m. NS, $P>0.05,{ }^{*} P<0.05,{ }^{* *} P<0.01$; $\S P<0.05$; $\S \S P<0.01$ for interaction.

absence of CRF conditioned place preference persisted for at least 90 days after repeated stress exposure $\left(\mathrm{F}_{2,20}=6.870, P<0.05\right.$, oneway ANOVA with Dunnett's post hoc; Fig. $4 \mathrm{~b}$ and Supplementary Fig. 14b). Similarly, endogenously released CRF no longer stimulated exploration of a novel object when tested 7 days after stress exposure (stimulus by drug, $\mathrm{F}_{1,16}=0.004, P>0.05$, two-way repeated-measures ANOVA; Supplementary Fig. 15) showing that severe stress abolished the function of CRF in the nucleus accumbens to stimulate appetitive responses to arousing stimuli (unpaired $t$-test, $P<0.05$, Fig. $4 \mathrm{c}$ ). Therefore, these findings demonstrate the long-term loss of a regulatory mechanism of motivated behaviour after severe stress.

Major depressive disorder has a lifetime prevalence of $17 \%$, making it one the world's greatest public-health concerns ${ }^{26}$; however, its molecular foundation has been elusive. Patients suffering from this disorder present with constellations of symptoms that include loss of affect, cognitive impairment and homeostatic imbalance ${ }^{27}$; symptoms that are presumably precipitated by dysregulation of several brain regions $s^{4}$. It is established that glucocorticoid-dependent hippocampal atrophy is a critical mediator of cognitive impairment in depression such as memory loss ${ }^{4}$. More recently, disruption of nucleus accumbens function has been implicated in the affective symptoms of depression ${ }^{4}$. In the current work, we studied the actions of CRF on neurotransmission within this brain region in an attempt to connect pathological stress-related neuroadaptation with the shift in affect observed in depressed patients.

CRF receptors are distributed widely throughout the brain ${ }^{8}$ and mediate disparate effects (see Supplementary Discussion). Our data highlight the specificity of the local action of both exogenously applied and endogenously released CRF in the nucleus accumbens in producing a positive, rather than negative, subjective state by increasing dopamine release. Importantly, we show that severe stress disables this capacity of CRF to positively regulate dopamine, removing CRF's appetitive qualities, leaving a negative perceptual bias. This dysregulation is mediated by glucocorticoid, but not $\kappa$-opioid, receptors and is not ameliorated by acute prophylactic administration of a selective serotonin-reuptake inhibitor. Glucocorticoid signalling has been shown to have genomic repressive effects on the CRF system, in particular the downregulation of CRFR $1^{24}$. Genetic deletion of the CRFR1 gene selectively from dopamine neurons increases anxiety-like behaviour $^{28}$, demonstrating further that disruption of CRF-dopamine interactions alone is sufficient to produce a negative affective state similar to that following severe stress ${ }^{29}$.

Collectively, our data show a specific defect in the regulation of dopamine transmission in the nucleus accumbens as a consequence of exposure to stress that induces depression-like behaviour. Depressive disorders produce a profound change in the perception of, and behavioural response to, acute stressors and other arousing environmental stimuli that elicit CRF signalling. Taken together, our findings provide a neurobiological mechanism for the affective shift from engagement of the environment to withdrawal following severe stress, central to the manifestation of major depressive disorder.

\section{METHODS SUMMARY}

Subjects. Male C57BL/6 mice aged $>50$ days had ad libitum access to food and water. Mice housed together (two to four per cage) were subjected to the same behavioural treatments. All animal procedures were approved by the University of Washington Institutional Animal Care and Use Committee.

Neuroanatomy. Immunohistochemistry was carried out as described previously ${ }^{20}$. Sections were incubated for $24 \mathrm{~h}$ with a mixture of mouse anti-tyrosine hydroxylase 1:1,000 and rabbit anti-CRF (peptide) 1:150, and chicken anti-ChAT antibody $1: 150$ or rabbit anti-CRFR1 or goat anti-CRFR2 (1:100 to $1: 500)$, then incubated in the appropriate fluorescently tagged secondary antibodies (1:500), and were imaged using epifluorescent and confocal microscopes. Transmission electron microscopy was carried out as previously described ${ }^{30}$.

Fast-scan cyclic voltammetry. $250-\mu \mathrm{m}$ coronal slices containing the nucleus accumbens were continuously perfused $\left(1.5-2.0 \mathrm{ml} \mathrm{min}^{-1}\right)$ with oxygenated artifical cerebrospinal fluid (aCSF) maintained at $31-33^{\circ} \mathrm{C}$. The potential at a carbon-fibre electrode was held at $-0.4 \mathrm{~V}$ versus $\mathrm{Ag} / \mathrm{AgCl}$, ramped to $+1.3 \mathrm{~V}$ and back to $-0.4 \mathrm{~V}\left(400 \mathrm{~V} \mathrm{~s}^{-1}\right)$ every $100 \mathrm{~ms}$. A single biphasic electrical pulse ( $2 \mathrm{~ms}$ per phase, $100-500 \mu \mathrm{A}$ ) was applied to the slice to evoke dopamine release. Conditioned place preference. A three-compartment place-conditioning apparatus was used to measure preference as described previously ${ }^{20}$. On days 2 and 3 , mice received two intra-accumbens microinjections per day: one injection of aCSF and one injection of CRF ( $500 \mathrm{ng}$ in $200 \mathrm{nl}$ per side) paired with different chambers. On day 4, mice were allowed free access to the apparatus for $30 \mathrm{~min}$. At the end of behavioural testing, cannulae placements were assessed.

Novel-object exploration. The novel object exploration assay was similar to an assay that has been described previously ${ }^{28}$. Animals received bilateral intra-accumbens microinfusions of vehicle or $\alpha$-helical CRF ( $500 \mathrm{ng}$ in $200 \mathrm{nl}$ ) counterbalanced across 2 days of testing. On each testing day, the animal was exposed to a new novel object.

Full Methods and any associated references are available in the online version of the paper.

\section{Received 13 May 2011; accepted 23 July 2012.}

Published online 19 September; corrected online 17 October 2012 (see full-text HTML for details).

1. Korte, S. M., Koolhaas, J. M., Wingfield, J. C. \& McEwen, B. S. The Darwinian concept of stress: benefits of allostasis and costs of allostatic load and the trade-offs in health and disease. Neurosci. Biobehav. Rev. 29, 3-38 (2005).

2. Beck, A. T. The evolution of the cognitive model of depression and its neurobiological correlates. Am. J. Psychiatry 165, 969-977 (2008).

3. Clark, D. A. \& Beck, A. T. Cognitive theory and therapy of anxiety and depression: convergence with neurobiological findings. Trends Cogn. Sci. 14, 418-424 (2010).

4. Nestler, E. J. et al. Neurobiology of depression. Neuron 34, 13-25 (2002).

5. Wang, B. et al. Cocaine experience establishes control of midbrain glutamate and dopamine by corticotropin-releasing factor: a role in stress-induced relapse to drug seeking. J. Neurosci. 25, 5389-5396 (2005).

6. Merali, Z., McIntosh, J. \& Anisman, H. Anticipatory cues differentially provoke in vivo peptidergic and monoaminergic release at the medial prefrontal cortex. Neuropsychopharmacology 29, 1409-1418 (2004).

7. Gallagher, J. P., Orozco-Cabal, L. F., Liu, J. \& Shinnick-Gallagher, P. Synaptic physiology of central CRH system. Eur. J. Pharmacol. 583, 215-225 (2008). 
8. Steckler, T. \& Holsboer, F. Corticotropin-releasing hormone receptor subtypes and emotion. Biol. Psychiatry 46, 1480-1508 (1999).

9. Peciña, S., Schulkin, J. \& Berridge, K. C. Nucleus accumbens corticotropinreleasing factor increases cue-triggered motivation for sucrose reward: paradoxical positive incentive effects in stress? BMC Biol. 4, 8 (2006).

10. Lim, M. M. et al. CRF receptors in the nucleus accumbens modulate partner preference in prairie voles. Horm. Behav. 51, 508-515 (2007).

11. Aragona, B. J. et al. Nucleus accumbens dopamine differentially mediates the formation and maintenance of monogamous pair bonds. Nature Neurosci. 9 , 133-139 (2006).

12. Lex, A. \& Hauber, W. Dopamine D1 and D2 receptors in the nucleus accumbens core and shell mediate Pavlovian-instrumental transfer. Learn. Mem. 15, 483-491 (2008).

13. Waselus, M., Nazzaro, C., Valentino, R. J. \& Van Bockstaele, E. J. Stress-induced redistribution of corticotropin-releasing factor receptor subtypes in the dorsal raphe nucleus. Biol. Psychiatry 66, 76-83 (2009).

14. Timpl, P. et al. Impaired stress response and reduced anxiety in mice lacking a functional corticotropin-releasing hormone receptor 1. Nature Genet. 19, 162-166 (1998).

15. Bale, T. L. et al. Mice deficient for corticotropin-releasing hormone receptor-2 display anxiety-like behaviour and are hypersensitive to stress. Nature Genet. 24 410-414 (2000).

16. Cador, M., Ahmed, S. H., Koob, G. F., Le Moal, M. \& Stinus, L. Corticotropin-releasing factor induces a place aversion independent of its neuroendocrine role. Brain Res. 597, 304-309 (1992).

17. Oldfield, E. H. et al. Active clearance of corticotropin-releasing factor from the cerebrospinal fluid. Neuroendocrinology 40, 84-87 (1985).

18. Fink, J. S. \& Smith, G. P. Mesolimbic and mesocortical dopaminergic neurons are necessary for normal exploratory behavior in rats. Neurosci. Lett. 17, 61-65 (1980).

19. Bale, T. L. Stress sensitivity and the development of affective disorders. Horm. Behav. 50, 529-533 (2006).

20. Bruchas, M. R. et al. Stress-induced p38 mitogen-activated protein kinase activation mediates к-opioid-dependent dysphoria. J. Neurosci. 27, 11614-11623 (2007).

21. Coryell, W. et al. The time course of nonchronic major depressive disorder. Uniformity across episodes and samples. National Institute of Mental Health Collaborative Program on the Psychobiology of Depression-Clinical Studies. Arch Gen. Psychiatry 51, 405-410 (1994).

22. Torres, G., Horowitz, J. M., Laflamme, N. \& Rivest, S. Fluoxetine induces the transcription of genes encoding c-fos, corticotropin-releasing factor and its type 1

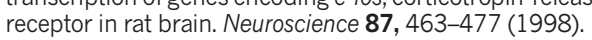

23. Bruchas, M. R. \& Chavkin, C. Kinase cascades and ligand-directed signaling at the kappa opioid receptor. Psychopharmacology (Berl.) 210, 137-147 (2010).

24. Iredale, P. A. \& Duman, R. S. Glucocorticoid regulation of corticotropin-releasing factor 1 receptor expression in pituitary-derived AtT-20 cells. Mol. Pharmacol. 51, 794-799 (1997).

25. Cryan, J. F. \& Mombereau, C. In search of a depressed mouse: utility of models for studying depression-related behavior in genetically modified mice. Mol. Psychiatry 9, 326-357 (2004).

26. Kessler, R. C. et al. Lifetime prevalence and age-of-onset distributions of DSM-IV disorders in the National Comorbidity Survey Replication. Arch. Gen. Psychiatry 62, 593-602 (2005); erratum 62, 768 (2005).

27. Gelenberg, A. J. Depression symptomatology and neurobiology. J. Clin. Psychiatry 71, e02 (2010)

28. Refojo, D. et al. Glutamatergic and dopaminergic neurons mediate anxiogenic and anxiolytic effects of CRHR1. Science 333, 1903-1907 (2011).

29. Chaki, S. et al. Anxiolytic- and antidepressant-like profile of a new CRF1 receptor antagonist, R278995/CRA0450. Eur. J. Pharmacol. 485, 145-158 (2004).

30. Reyes, B. A., Valentino, R. J. \& Van Bockstaele, E. J. Stress-induced intracellular trafficking of corticotropin-releasing factor receptors in rat locus coeruleus neurons. Endocrinology 149, 122-130 (2008).

Supplementary Information is available in the online version of the paper.

Acknowledgements This work was supported by National Institutes of Health grants F31-MH086269 (J.C.L.), F32-DA026273 (M.J.W.), R01-DA009082 (E.J.V.B.), R01-DA030074 (C.C.), R01-MH079292 and R01-DA016782 (P.E.M.P.), the National Science Foundation (N.G.H.) and NARSAD (P.E.M.P.). We thank C. Zietz, M. Miyatake and P. Groblewski for assisting with histological verification of cannula placement,

H. Gill for help with data analysis, D. Messinger for breeding and genotyping mice and N. Stella for use of a microscope. We thank M. Darvas and R. Palmiter for providing

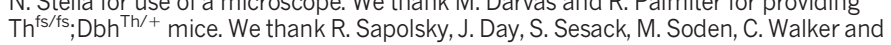
E. Horne for useful suggestions and insights.

Author Contributions J.C.L. performed immunohistochemistry. J.C.L. and N.G.H. carried out fast-scan cyclic-voltammetry experiments. J.C.L., M.J.W. and J.S.S. performed the behavioural experiments. B.A.S.R. and E.J.V.B. provided transmission electron microscopy data. J.C.L., M.J.W., C.C. and P.E.M.P. developed the conceptual and experimental framework, and J.C.L. and P.E.M.P. wrote the paper.

Author Information Reprints and permissions information is available at www.nature.com/reprints. The authors declare no competing financial interests. Readers are welcome to comment on the online version of the paper. Correspondence and requests for materials should be addressed to P.E.M.P. (pemp@uw.edu). 


\section{METHODS}

Subjects. Male C57BL/ 6 mice aged $>50$ days were maintained under a 12-h lightdark cycle (7:00 to 19:00 light) with access to standard food and water ad libitum. All procedures on animal subjects were approved by the University of Washington or Thomas Jefferson University Institutional Animal Care and Use Committee. Mice housed together (two to four per cage) were subjected to the same behavioural treatments.

Immunohistochemistry. We used perfusion, cryosectioning and immunohistochemistry procedures as described previousl $y^{20}$. Sections $(30 \mu \mathrm{m})$ were then incubated with a mixture of mouse anti-tyrosine hydroxylase 1:1,000 (Sigma) and either rabbit anti-CRF (peptide) 1:150 (Sigma) and chicken anti-ChAT antibody 1:150 (Invitrogen) or rabbit anti-CRFR1 or CRFR2 (Novus Biologicals) in blocking buffer for $24-36 \mathrm{~h}$ at room temperature. Sections were then washed with PBS, and detection was carried out using the fluorescent secondary antibody Alexa Fluor 488 goat anti-mouse immunoglobulin-G (IgG) 1:500, Alexa Fluor 555 goat anti-rabbit IgG and Alexa Fluor 633 goat anti-chicken IgG (Invitrogen) in blocking buffer for $2 \mathrm{~h}$ at room temperature. Sections were washed in PBS 3 times for $10 \mathrm{~min}$ and $0.1 \mathrm{M}$ phosphate buffer twice for $10 \mathrm{~min}$ and mounted on Superfrost plus slides. Sections were imaged with epifluorescence (Nikon) and confocal microscopes (Leica).

Transmission electron microscopy. Mice were perfused and brains were sectioned as described previously. Sections $(100 \mathrm{~nm})$ were processed using standard transmission-electron-microscopy procedures ${ }^{30,31}$. Sections were incubated in mouse anti-TH (1:1,000; Immunostar) and rabbit anti-corticotropinreleasing factor receptor (1:1,000; Santa Cruz Biotechnology) overnight at room temperature. Immunoperoxidase detection of tyrosine hydroxylase and silverintensified immunogold localization of CRFRs followed standard procedures ${ }^{30}$. Digital images were captured using the AMT advantage HR/HR-B CCD camera system (Advance Microscopy Techniques). Only tissue sections with good preservation of ultrastructural morphology and with both tyrosine hydroxylase and CRFR immunoreactivity clearly apparent in the tissue were used for the analysis. For immunogold labelling, profiles with at least two immunogold-silver particles within a cellular compartment in a single thin section were considered immunolabelled ${ }^{30,32}$. The cellular elements were classified according to a method described previously ${ }^{33,34}$.

Fast-scan cyclic voltammetry. Mice were quickly decapitated and the head placed in pre-oxygenated ice-cold artificial cerebrospinal fluid (aCSF) in which sucrose $(248 \mathrm{mM})$ was substituted for $\mathrm{NaCl}$. The brain was rapidly removed and blocked to isolate the anterior forebrain. Coronal slices $(250 \mu \mathrm{m})$ containing the nucleus accumbens were prepared using methods described previously ${ }^{35}$, placed in a recording chamber and continuously perfused $\left(1.5-2.0 \mathrm{ml} \mathrm{min}^{-1}\right)$ with oxygenated aCSF (in mM: $\mathrm{NaCl}, 124 ; \mathrm{KCl}, 2.5 ; \mathrm{NaH}_{2} \mathrm{PO}_{4}, 1.25 ; \mathrm{MgSO}_{4}, 2.0 ; \mathrm{CaCl}_{2}, 2.0$; dextrose, 10; and $\left.\mathrm{NaHCO}_{3}, 26\right)$ maintained at $31-33{ }^{\circ} \mathrm{C}$. Carbon-fibre electrodes were fabricated using a Sutter P-97 puller. Carbon-fibre electrodes (working electrodes) were hand cut to approximately $100-150 \mu \mathrm{m}$ past the capillary tip. The potential at a carbon-fibre electrode was held at $-0.4 \mathrm{~V}$ versus $\mathrm{Ag} / \mathrm{AgCl}$, ramped to $+1.3 \mathrm{~V}$ and back to $-0.4 \mathrm{~V}\left(400 \mathrm{~V} \mathrm{~s}^{-1}\right)$ every $100 \mathrm{~ms}$. A single biphasic electrical pulse ( $2 \mathrm{~ms}$ per phase, $100-500 \mu \mathrm{A}$ ) was applied to the slice to evoke dopamine release. Swim stress. Mice were subjected to either a single 15 -min swim with a $24-\mathrm{h}$ recovery period, or a 2-day swim stress in which they were exposed to a 15-min swim session on day 1 , then $24 \mathrm{~h}$ later on day 2 , were exposed to 4 swim sessions of 6 min separated by $6 \mathrm{~min}$, conducted under bright light (690-700 lx) conditions. Water temperature was maintained at $29-31^{\circ} \mathrm{C}$. Animals were removed from the water if they became completely submerged for $>1 \mathrm{~s}$ at any time during the paradigm. Some animals were killed at $30 \mathrm{~min}, 7,30$ or 90 days after the final swim session of the 2-day protocol, and nucleus accumbens slices were prepared.
Cannulations. Animals were anaesthetized with isoflurane and cannulation surgeries were carried out using a stereotaxic alignment system, similar to methods described previously ${ }^{20}$. Double-guide cannulas (26 gauge, $3.5 \mathrm{~mm}$ from pedestal, $2 \mathrm{~mm}$ separation; Plastics One) were placed in the nucleus accumbens core at $\pm 1 \mathrm{~mm}$ lateral, $1 \mathrm{~mm}$ posterior from bregma and $3.5 \mathrm{~mm}$ below the skull. Guide cannulas were anchored using dental cement, and dummy internal cannulas were placed inside until injection. Mice were injected intracerebroventricularly by placing a 33-gauge internal cannula (Plastics One) into the guide cannula.

Conditioned place preference. Animals were allowed to recover from surgery for at least 7 days. All animals were handled for 4 days before the pre-test day. Animals assigned to the stress-exposed group were subjected to the 2-day swim-stress paradigm after recovery; animals were not included if they did not show normal swimming responses. Stress-exposed animals began CRF conditioning 7 or 90 days after the final swim session. A three-compartment place-conditioning apparatus was used to measure preference as described previously ${ }^{20}$. On days 2 and 3, mice received 2 injections per day: 1 injection of aCSF and 1 injection of CRF (500 ng per $200 \mathrm{nl}$ ) paired with different chambers at $125 \mathrm{nl} \mathrm{min}^{-1}$. On day 4 , mice were once again allowed free access to the entire apparatus for $30 \mathrm{~min}$. After the conclusion of behavioural testing, cannulae placements were assessed. Mice with cannula placements outside the accumbens were excluded from the study. 6-OHDA lesion and high-performance liquid chromatography. Mice were injected with either 6-OHDA ( $2 \mu \mathrm{g}$ per $500 \mathrm{nl}$; Sigma) or vehicle $(0.9 \% \mathrm{NaCl}$ $0.1 \%$ ascorbate). After the conclusion of behavioural testing, a tissue core (approximately $2 \times 2 \times 1 \mathrm{~mm}$ ) of the ipsilateral and contralateral accumbens of each animal was microdissected, rapidly frozen in liquid nitrogen and stored in microcentrifuge tube at $-80^{\circ} \mathrm{C}$ until processed for tissue dopamine content. High-performance liquid chromatography (HPLC) was used to measure monoamine content by the Neurochemistry Core Laboratory at the Vanderbilt University Center for Molecular Neuroscience Research.

Novel object exploration. Mice were cannulated, allowed to recover from surgery and handled for 4 days before being subjected to a novel object exploration assay similar to previously described ${ }^{28}$. In brief, on test day 1 , mice were given bilateral intra-accumbens microinfusions of either vehicle (lactated ringer's with $1 \%$ acetic acid) or $\alpha$-helical CRF $(2 \mu \mathrm{g})$ and were allowed to habituate in an open field for $15 \mathrm{~min}$. Subsequently, a novel object was introduced and exploratory behaviour of the novel object was measured for an additional $15 \mathrm{~min}$. On test day 2 , the animals received the alternative pharmacological treatment to that which they received on day 1 , were allowed to habituate again in the open field and then exposed to a second novel object. Both the pharmacological treatment and the novel objects were counter-balanced across test days. Identically to the place-conditioning experiments, 1 group of mice were exposed to swim stress 7 days before test day 1 .

31. van Bockstaele, E. J., Sesack, S. R. \& Pickel, V. M. Dynorphin-immunoreactive terminals in the rat nucleus accumbens: cellular sites for modulation of target neurons and interactions with catecholamine afferents. J. Comp. Neurol. 341, $1-15$ (1994).

32. Reyes, B. A., Fox, K., Valentino, R. J. \& Van Bockstaele, E. J. Agonist-induced internalization of corticotropin-releasing factor receptors in noradrenergic neurons of the rat locus coeruleus. Eur. J. Neurosci. 23, 2991-2998 (2006).

33. Peters, A., Palay, S. L. \& Webster, H. D. The Fine Structure of the Nervous System (Oxford Univ. Press, 1991)

34. Peters, A. \& Palay, S. L. The morphology of synapses. J. Neurocytol. 25, 687-700 (1996).

35. Bruchas, M. R., Land, B. B., Lemos, J. C. \& Chavkin, C. CRF1-R activation of the dynorphin/kappa opioid system in the mouse basolateral amygdala mediates anxiety-like behavior. PLOS ONE 4, e8528 (2009). 